\title{
When is Helicobacter pylori infection acquired?
}

\author{
D J E Cullen, B J Collins, K J Christiansen, J Epis, J R Warren, I Surveyor, K J Cullen
}

\begin{abstract}
Cross sectional surveys have shown an increasing prevalence of Helicobacter pylori ( $H$ pylori) infection with increasing age in Western populations. The aim of this study was to examine the pattern of acquisition of $H$ pylori infection over a 21 year period in a group of 141 adults who had blood samples and serum stored in 1969, 1978, and 1990. A prevalence of $\boldsymbol{H}$ pylori antibody of $39 \%$ in 1969 serum samples, $40.9 \%$ in 1978 , and $34.8 \%$ in 1990 was found when assessed by an enzyme linked immunosorbent assay (ELISA). Of the 86 subjects who were seronegative in 1969 , only six (7\%) were seropositive in 1990 . These data suggest that a cohort effect may contribute to the pattern of increasing prevalence of $\boldsymbol{H}$ pylori infection seen with increasing age. Acquisition of infection in adults is rare. It is unlikely, therefore, that reinfection will occur after successful eradication.

(Gut 1993; 34: 1681-1682)
\end{abstract}

Previous studies have shown an increasing prevalence of Helicobacter pylori ( $H$ pylori) antibody titres with increasing age in Western populations. ${ }^{12}$ One explanation for this finding would be that $H$ pylori infection is acquired by people throughout their lives. Alternatively, it may have been a commoner infection in past generations and the high prevalence of antibody titres in elderly people may reflect their greater exposure to the infection in years gone by; in other words, a cohort effect. If this latter proposition is true, it would suggest that most patients in whom $H$ pylori has been eradicated are unlikely to become reinfected at a later date.

By measuring $H$ pylori antibody titres in serum samples collected and stored between 1969 and 1990 , we aimed at describing the pattern of acquisition of $H$ pylori infection over a 21 year period in an adult population and thereby to determine the explanation for the higher prevalence of $H$ pylori antibody with increasing age found in Western society.

Royal Perth Hospital and the Busselton Population Studies Group, Australia D J E Cullen

B J Collins

K J Christiansen

J Epis

R Warren

I Surveyor

K J Cullen

Correspondence to:

Dr D J E Cullen, Departmen of Therapeutics, Queen's Medical Centre, Nottingham NG7 2UH.

Accepted for publication 27 April 1993

\section{Methods}

The Busselton population study is a series of cross sectional surveys conducted in a normal community population in Busselton, a small coastal town (population 9000) in the south west of Western Australia, every three years from 1966 to $1981 .{ }^{3}$ Serum was taken from every participant at the surveys in 1969 and 1978 and placed in deep frozen storage $\left(-30^{\circ} \mathrm{C}\right)$. Additional serum samples were taken in December 1990 from a randomly selected cohort of 141 people aged $40-65$ years. There was a male predominance because this group was initially selected for the purpose of a study of sleep apnoea, a condition that is commoner in men. Neither sleep apnoea nor any other medical condition was a prerequisite for inclusion in this sampling.

One hundred and forty one people were chosen for our study. The inclusion criteria were that all subjects were current residents of Busselton, aged between 40 and 65 years in December 1990, had been randomly selected except for a deliberate male to female bias for the purposes of the sleep study, and had serum available from 1969 and 1990. An acid glycine extract ELISA technique was used to test for $H$ pylori as described by Goodwin et $a l,{ }^{4}$ and was performed in 1991 on serum samples, which had been taken in 1969, 1978, and November/ December 1990. At a titre of 300 ELISA units, the assay has a sensitivity of $86 \%$ and a specificity of $96 \%$ when measured against the standard of histological examination or culture of endoscopic antral biopsy specimens or both (in house data based on 100 patients of whom 62 had $H$ pylori gastritis).

\section{Results}

There were 141 subjects with a mean age in December 1969 of 33.7 years (range 20.2-44.0) and in December 1990 of 54.7 years (range $41 \cdot 2-$ $64 \cdot 0)$. Men predominated with $103(73 \%)$ compared with $38(27 \%)$ women. The mean age of the men in December 1990 was 54.2 years (range $41 \cdot 3-65 \cdot 0$ ) and of the women $56 \cdot 0$ years (range 41-1-64-4). All 141 subjects had a serum sample from both 1969 and 1990 available for analysis and $110(78 \%)$ also had a sample available from 1978.

The prevalence of $H$ pylori antibody in the serum samples showed no significant change at the three timepoints tested, $39 \%$ being seroposi-

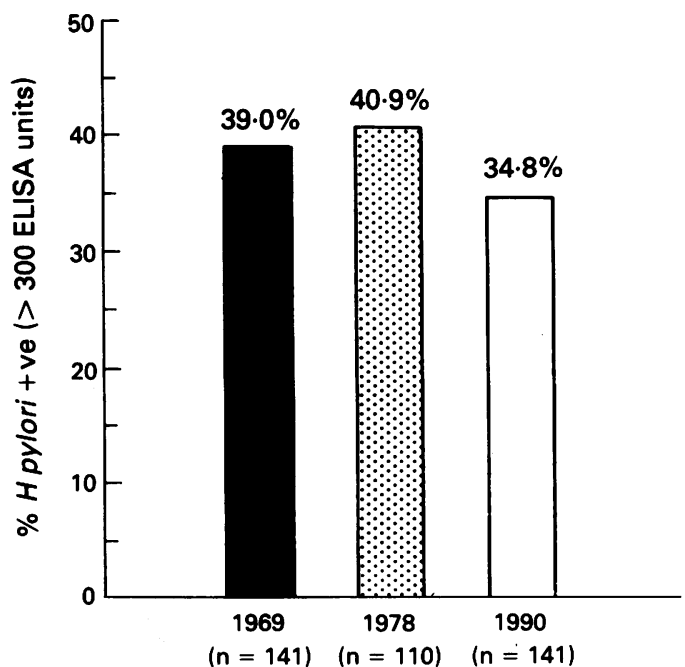

Prevalence of Helicobacter pylori antibody in 1969, 1978, and 1990. 
Results of antibody testing of serum from 1978 and 1990 of subjects who were seropositive or seronegative for $\mathrm{H}$ pylori antibodies in serum samples from 1969

\begin{tabular}{llll}
\hline & & \multicolumn{2}{l}{$\begin{array}{l}\text { Serological state on same } \\
\text { subjects retested in }\end{array}$} \\
\cline { 3 - 4 } Serological state in 1969 & & $1978(\%)$ & $1990(\%)$ \\
\hline Seropositive $\mathrm{n}=55$ & $+\mathrm{ve}$ & $37 / 42(88 \cdot 1)$ & $43 / 55(78 \cdot 2)$ \\
Seronegative $\mathrm{n}=86$ & -ve & $5 / 42(11 \cdot 9)$ & $12 / 55(21 \cdot 8)$ \\
& $+\mathrm{ve}$ & $8 / 68(11 \cdot 7)$ & $6 / 86(7 \cdot 0)$ \\
& -ve & $60 / 68(88 \cdot 3)$ & $80 / 86(93 \cdot 0)$ \\
\hline
\end{tabular}

tive in $1969,40.9 \%$ in 1978 , and $34.8 \%$ in 1990 (Figure). Of the 55 serum samples taken in 1969 that were positive, 42 were retested in 1978 and of these, $37 / 42(88 \cdot 1 \%)$ were still seropositive. All 55 seropositive subjects from 1969 had serum samples taken in 1990 and 43/55 (78.2\%) remained positive. No initially seropositive subject who subsequently was seronegative in 1978 became positive in 1990 (Table).

Of the serum samples taken in $1969,86 / 141$ (61\%) were negative for $H$ pylori antibody. Of these 86 subjects, 68 had samples available from 1978 and $60 / 68(88.2 \%)$ remained negative. All 86 subjects had samples from 1990 tested and $80 / 86$ (93\%) were seronegative (Table). Of the eight subjects, initially seronegative but who became positive in 1978, four remained positive whereas four reverted to seronegative in 1990.

As only 6/86 (7\%) subjects who were seronegative in 1969 were seropositive 21 years later, this suggests a seroconversion rate of only $0.33 \%$ per person year ( $95 \%$ confidence intervals 0.08 to $0.59 \%$ per person year). This is a minimum estimate, however, because our 1978 data, although incomplete, showed that four subjects acquired $H$ pylori antibody and at a later date reverted to seronegative.

\section{Discussion}

Recent cross sectional surveys of Australian blood donors ${ }^{1}$ and healthy white Americans ${ }^{2}$ showed that $10-14 \%$ of $30-40$ year old subjects had $H$ pylori antibodies whereas $37-45 \%$ of $50-60$ year old subjects were antibody positive. The results from our 1990 serum samples $(34 \cdot 8 \%$ of subjects of mean age $54 \cdot 7$ years were seropositive) were similar to those of the cross sectional surveys. By contrast, our 1969 results showed an unexpectedly high prevalence of $H$ pylori antibodies ( $39 \%$ of subjects of mean age $33 \cdot 7$ years).

The two key findings of our study, therefore, were firstly that $H$ pylori infection was more common than expected in our population in 1969 and secondly that acquisition of infection over the subsequent 21 years was a rare occurrence. These findings suggest that a cohort effect may be at least in part responsible for the pattern described in recent surveys of increasing prevalence of $H$ pylori antibodies with age. As our study has also shown that most subjects who were seropositive in 1969 remained so over the next 21 years, it is probable that the high prevalence of $H$ pylori antibodies seen in elderly subjects is at least in part a reflection of greater exposure to the infection in earlier years.

One other study, in which a group of 341 epidemiologists had $H$ pylori antibody state assessed over a mean period of 8.5 years, also showed a low rate of seroconversion to a positive antibody state over time $(0.49 \%$ per person year). ${ }^{5}$ Although this was a very highly selected study group, the results were in agreement with our findings.

Our 1978 data detected four subjects who seemed to acquire and then lose $H$ pylori antibodies. These subjects had comparatively low positive titres in 1978 and may have been false positives. Alternatively, some subjects may require $H$ pylori infection and then clear it spontaneously or with the aid of antibiotic treatment, perhaps given for some intercurrent respiratory or urinary tract infection.

It is possible that the ELISA antibody testing on serum may not be reliable in that antibody may be lost if storage is inadequate and there is frequent freezing and thawing. The $H$ pylori antibody positivity rate of $39 \%$ of young adults in 1969 is somewhat higher than that reported by other surveys and the consistency of our antibody results over the 21 year period that the testing is valid.

In conclusion, our findings suggest that $H$ pylori infection may have been predominantly acquired at a young age in the past. Our data also imply that it may be becoming rarer in Western societies as it is difficult otherwise to reconcile our findings with the greater prevalence of $H$ pylori antibodies found in more elderly subjects in Western populations. An interesting speculation is that the decline in $H$ pylori infection over the past few decades would account at least in part for the reported decline in duodenal ulcer disease in Western populations. ${ }^{6}$ Furthermore, because $H$ pylori infection is rarely acquired in adult life, reinfection would not be expected in adult patients whose infection is successfully eradicated. This finding provides support for the belief that adequate treatment of $H$ pylori infection will give longterm protection from duodenal ulcer recurrence.

The authors thank Elsbeth Inglis, Helen Gaunt, Royal Perth Foundation, Biostatistics Unit Queen Elizabeth II Medica Centre, Department of Immunology (Royal Perth Hospital) and Peters Ice Cream Company for advice and support for this study.

1 Mitchell HM, Lee A, Berkowitz J, Borody T. The use of serology to diagnose active Campylobacter pylori infection. Med F Aust 1988; 149: 604-9.

2 Graham DY, Malaty HM, Evans DG, Evans DJ, Klein PD, Adam E. Epidemiology of Helicobacter pylori in an asymptomatic population in the United States. Gastroenterology 1991; 100: 1495-501.

3 Welborn TA, Cumpston GN, Cullen KJ, Curnow DH, McCall MG, Stenhouse NS. The prevalence of coronary heart disease and associated factors in an Australian rural community. and associated factors in an Aust

4 Goodwin CS, Blincow E, Peterson G, Sanderson C, Cheng W Marshall BJ, et al. Enzyme linked immunosorbent assay for Marshall BJ, et al. Enzyme linked immunosorbent assay for Campylobacter pyloridis: correlation with presence of Campylobacter

5 Parsonnet J, Blaser MJ, Perez-Perez GI, Hargrett-Bean N, Tauxe RV. Symptoms and risk factors of Helicobacter pylori infection in a cohort of epidemiologists. Gastroenterology 1992; 102: 41-6.

6 Sonnenberg A. Occurrence of a cohort phenomenon in peptic ulcer mortality from Switzerland. Gastroenterology 1984; 86 398-401. 